\title{
Deformation of a sound field caused by a manikin
}

\author{
Weinrich, Søren G.
}

\section{Published in:}

Acoustical Society of America. Journal

Link to article, DOI:

$10.1121 / 1.385485$

Publication date:

1981

\section{Document Version}

Publisher's PDF, also known as Version of record

Link back to DTU Orbit

Citation (APA):

Weinrich, S. G. (1981). Deformation of a sound field caused by a manikin. Acoustical Society of America. Journal, 69(3), 796-801. https://doi.org/10.1121/1.385485

\section{General rights}

Copyright and moral rights for the publications made accessible in the public portal are retained by the authors and/or other copyright owners and it is a condition of accessing publications that users recognise and abide by the legal requirements associated with these rights.

- Users may download and print one copy of any publication from the public portal for the purpose of private study or research.

- You may not further distribute the material or use it for any profit-making activity or commercial gain

- You may freely distribute the URL identifying the publication in the public portal

If you believe that this document breaches copyright please contact us providing details, and we will remove access to the work immediately and investigate your claim. 


\title{
Deformation of a sound field caused by a manikin
}

\author{
Søren G. Weinrich \\ The Acoustics Laboratory, Technical University of Denmark, DK-2800 Lyngby, Denmark \\ (Received 9 July 1980; accepted for publication 8 October 1980)
}

\begin{abstract}
Measurements of the deformation of a sound field by the presence of an anthropometric manikin are described. An approximate point source is placed at a distance of $3 \mathrm{~m}$ in front of the manikin at the height of the manikin's ears. In the horizontal plane at this height the resultant SPL is measured around the head at distances of $1 \mathrm{~cm}$ to $2 \mathrm{~m}$, measured from the tip of the nose. The signals were pure tones at $1,2,4,6,8$, and 10 $\mathrm{kHz}$. It was found that the presence of the manikin caused changes in the SPL of the sound field of at most $\pm 2.5 \mathrm{~dB}$ at.a distance of $1 \mathrm{~m}$ from the surface of the manikin. Only over an interval of approximately $20^{\circ}$ behind the manikin (i.e., opposite the sound source) did the manikin cause much larger changes, up to $9 \mathrm{~dB}$. These changes are caused by destructive interference between sounds coming from opposite sides of the manikin. In front of the manikin, the changes in SPL at this distance are within $\pm 1 \mathrm{~dB}$.
\end{abstract}

PACS numbers: 43.66.Yw, 43.20.Fn [BS]

\section{INTRODUCTION}

Recently, artifical heads-and torsos-(so-called anthropometric manikins) have been used in the measurement of the acoustical characteristics of hearing aids under approximately realistic conditions. An example of a manikin designed primarily for this purpose has been described in detail by Burkhard and Sachs (1975). Acoustic manikins may also be used in the calibration of headphones, in measurements of the attenuation of ear defenders (Burkhard, 1978), and in stereophonic recordings in connection with the evaluation of the acoustical quality of concert halls, auditoriums, etc. (Wikens, 1972; Kuhl and Plantz, 1975).

A manikin causes a deformation in its neighborhood of the sound field into which it is introduced. It is important to know the spatial extent of this deformation in order to be able to specify, for example, the best location of a control microphone to be used to maintain a constant sound pressure at a given point in the field (Preves, 1978; Burkhard, 1978). Such knowledge is also important for specifying the dimensions of the room in which the manikin is to be placed, and for determining the minimum acceptable distance to measuring equipment that must be present in the room.

The present investigation seeks to determine the deformation of a given sound field in the neighborhood of the manikin described by Burkhard and Sachs, (1975) designated KEMAR ${ }^{R}$. The manikin is placed in a free,

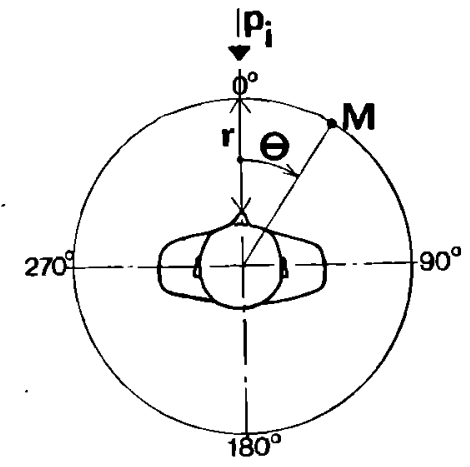

FIG. 1. The geometry of the measuring system. progressive sound field of frontal incidence. To determine this deformation, the difference between the SPL of the resultant field and the SPL of the undisturbed field at a given point in the neighborhood of the manikin is measured. This quantity is termed $\Delta L_{\rho}$ and is thus defined as

$$
\Delta L_{\mathrm{p}}=20 \log P_{\text {ras }} / P_{i}(\mathrm{~dB})=L_{\text {res }}-L_{i},
$$

where $P_{\text {res }}$ and $P_{i}$ are the sound pressure of the resultant field and the undisturbed field, respectively, and $L_{\text {res }}$ and $L_{i}$ are the corresponding sound pressure levels.

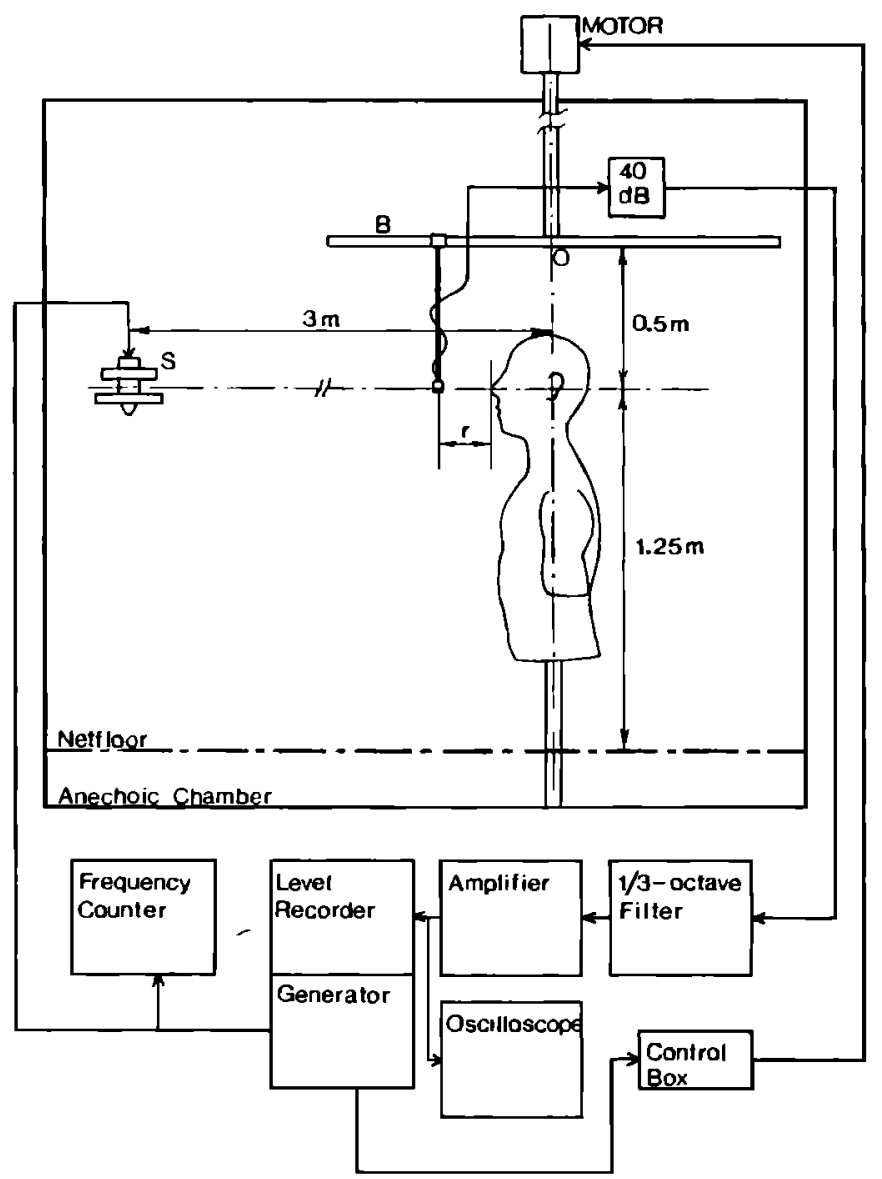

FIG. 2. The experimental setup. 
This investigation is pertinent not only to various practical problems, but also to a mathematical model of the human head and torso. The measured values of $\Delta L_{p}$ were to be compared to calculated values of $\Delta L_{p}$, but this part of the investigation so far has met with rather limited success, especially at frequencies above $3 \mathrm{kHz}$. The model will therefore not be further discussed in this paper.

Since time could not permit measuring throughout the whole neighborhood of the manikin at all audible frequencies, measurements were limited to the horizontal plane through the ears of the manikin. The sound source was also placed in this plane, in front of the manikin.

\section{MEASURING PROGRAM AND EXPERIMENTAL SETUP}

Figure 1 shows the manikin placed in a sound field of frontal incidence $p_{i}$. The microphone $(M)$ was used to measure $\Delta L_{p}$ as defined in Eq. (1). The measurements were carried out as a function of the angle $\theta$ from $0^{\circ}$ to $360^{\circ}$. The signals were pure tones at $1,2,4,6$,
8 , and $10 \mathrm{kHz}$. Measurements were made with the microphone at the following distances $(r)$ from the tip of the nose of the manikin to the actual measuring circle:

$$
\begin{aligned}
r & =1,2,3, \ldots, 48,49,50 \mathrm{~cm}, \\
\text { and } r & =55,60,65, \ldots, 90,95,100 \mathrm{~cm}, \\
\text { and } r & =125,150,175,200 \mathrm{~cm} .
\end{aligned}
$$

The range of the measuring frequencles was chosen according to the following considerations: At frequencies below $1 \mathrm{kHz}$ the wavelength of the sound is large compared with the dimensions of the head and torso. Therefore the sound field in the neighborhood of the manikin ought not to deviate much from the undisturbed free field. A small introductory investigation at low frequencies confirmed this, showing maximum deviations of 3 to $4 \mathrm{~dB}$ near the manikin and less than $1 \mathrm{~dB}$ at a distance of $50 \mathrm{~cm}$.

The upper limit of the measuring frequencies was chosen because measurements on hearing aids (for which purpose KEMAR was primarily constructed) usually terminate at 8 or $10 \mathrm{kHz}$. Measurements of higher frequencies would also have placed severe demands on the experimental setup, especially with re-
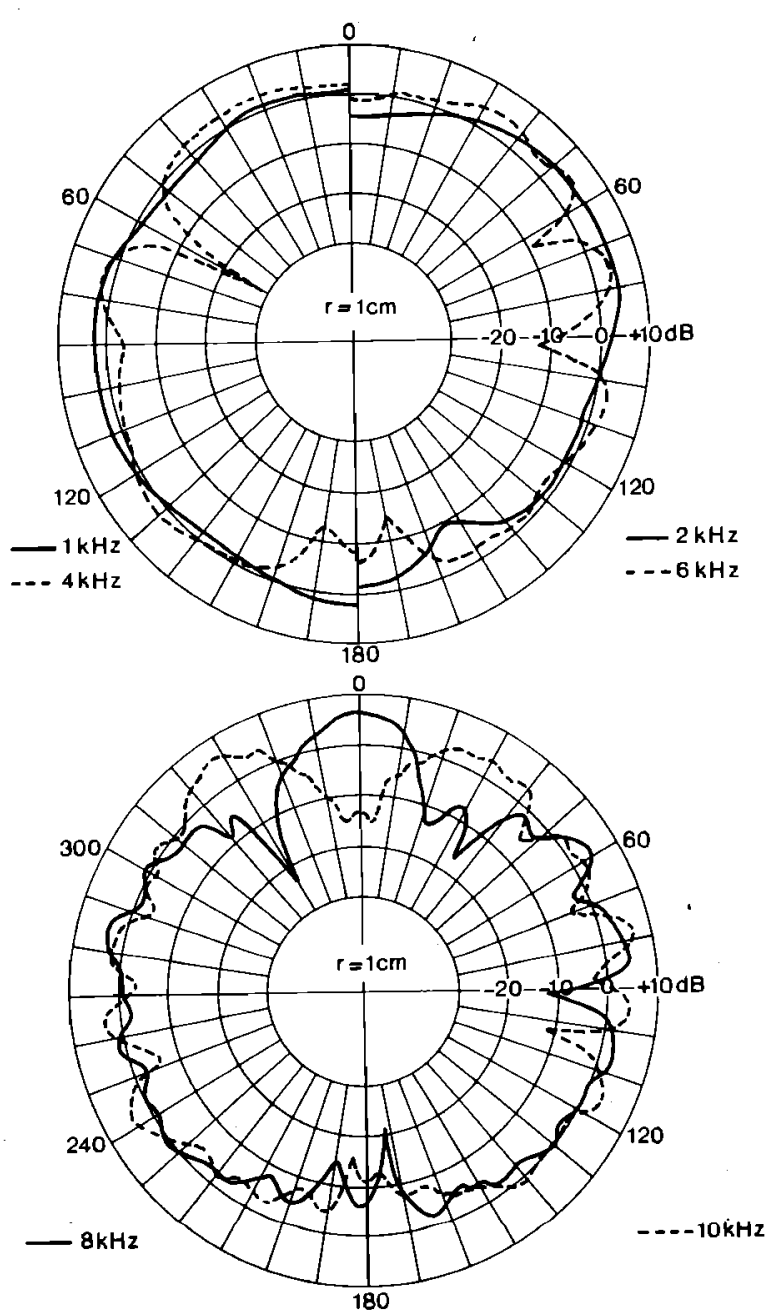

FIG. 3. Difference between SPL of resultant field and incident field $\Delta L_{p}(\mathrm{~dB})$ as a function of $\Theta$, for $r=1 \mathrm{~cm}$.
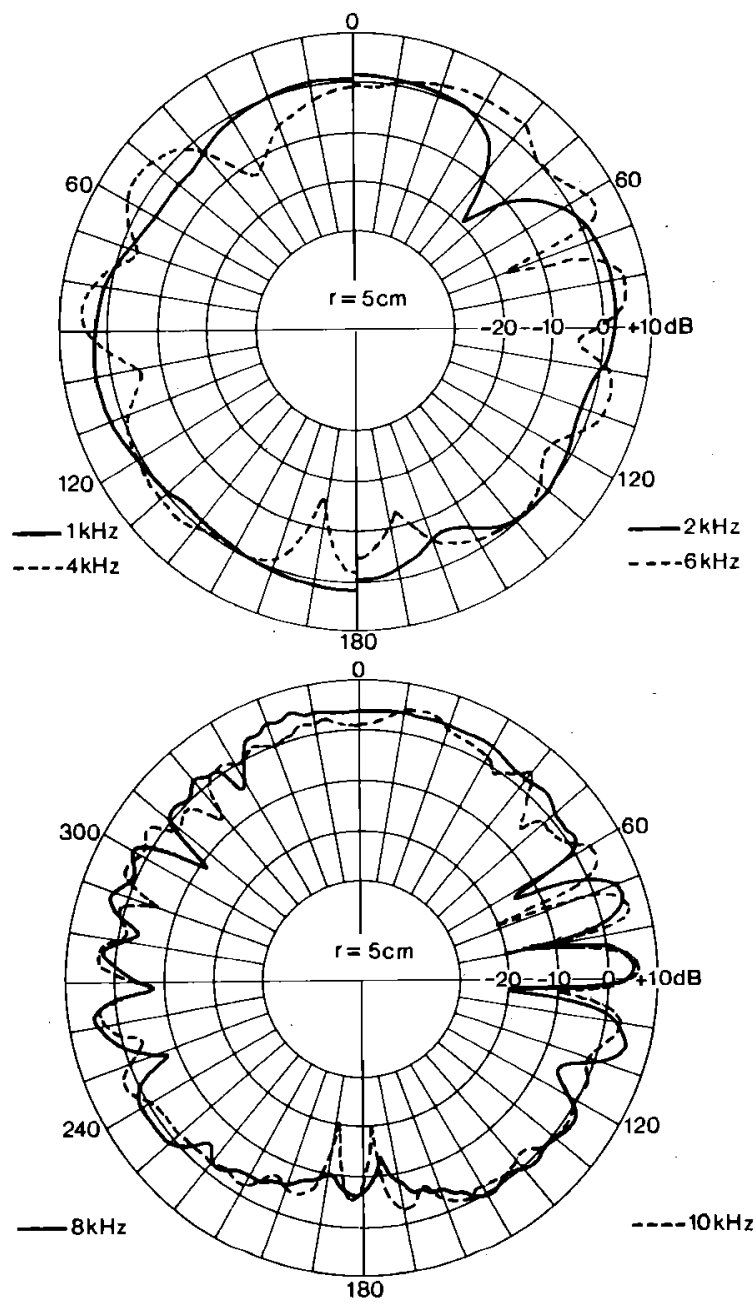

FIG. 4. Difference between SPL of resultant field and incident field $\Delta L_{p}(\mathrm{~dB})$ as a function of $\Theta$, for $r=5 \mathrm{~cm}$. 
gard to its mechanical construction.

The interval between the values of the distance parameter $r$ was chosen to permit a reasonable description of how $\Delta L_{p}$ depends on distance in the nearfield, at least at the lower test frequencies.

An interval of $1 \mathrm{~cm}$ within the range $1 \mathrm{~cm} \leqslant r \leqslant 50 \mathrm{~cm}$ gives a reasonably clear "three-dimensional" picture of the results up to $6 \mathrm{kHz}$ (see Figs. 12, 13, and 14).

Figure 2 shows the manikin placed in an anechoic room with the center of the head $125 \mathrm{~cm}$ above the net flcor of the room. The sound source $(S)$ is placed in the same plane a distance of $3 \mathrm{~m}$ from the center of the head. The microphone $(M)$ is mounted so that it can be rotated around a point $(O)$ directly above the center of the head. The position of the microphone relative to the point $O$ could be adjusted with an accuracy of $\pm 0.5 \mathrm{~mm}$. The point $O$ stayed within about $1 \mathrm{~mm}$ of the point directly above the center of the head during a complete revolution of the microphone. This means that the worst inaccuracy in the placement of the microphone in the horizontal plane is $1.5 \mathrm{~mm}$; the corresponding change in the resultant SPL rarely exceeded $1 \mathrm{~dB}$.
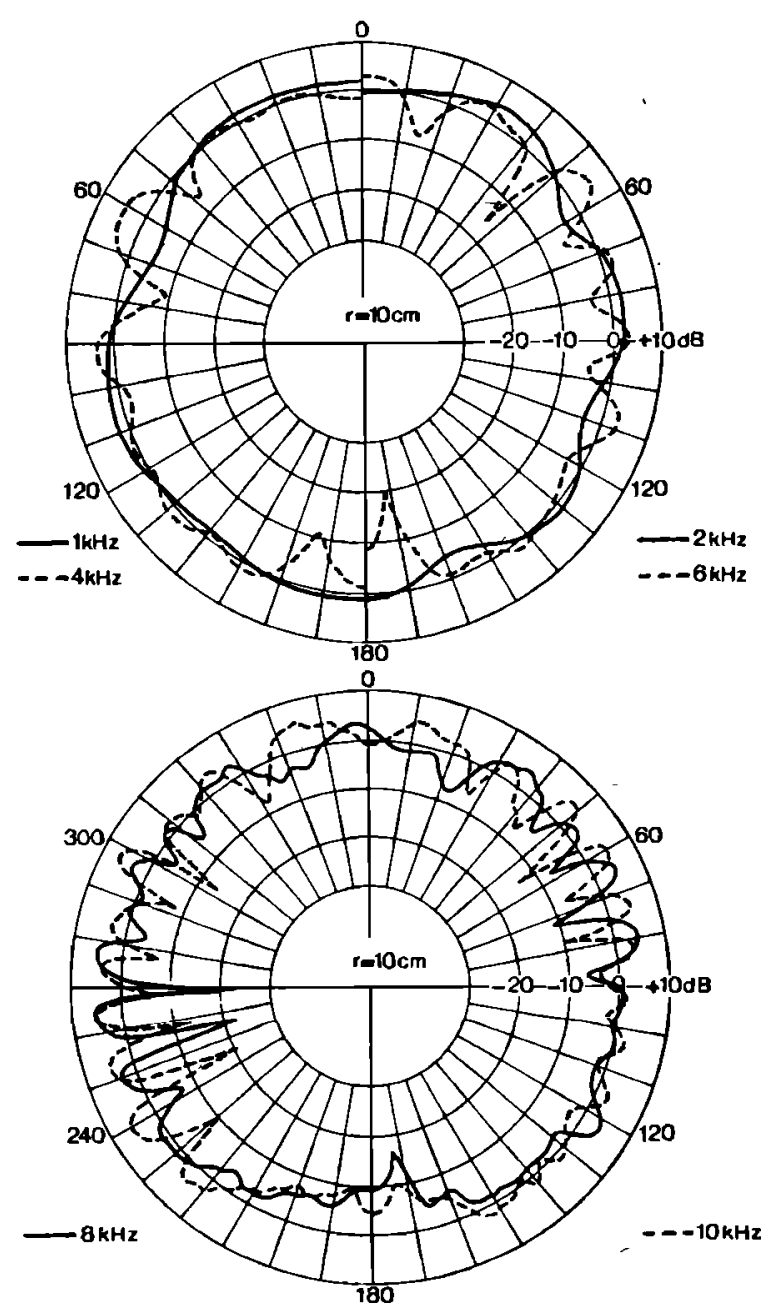

FIG. 5. Difference between SPL of resultant fleld and incident field $\Delta L_{p}(\mathrm{~dB})$ as a function of $\theta$, for $r=10 \mathrm{~cm}$.
Reflections from the mechanical arrangement were negligible, giving rise to maximum changes in $L_{\text {res }}$ of about $\pm 0.5 \mathrm{~dB}$ at $10 \mathrm{kHz}$. Also reflections from the net floor were found to be unimportant at a distance of $125 \mathrm{~cm}$ from the floor (see Ingerslev et al., 1967/68).

The signal from the microphone was passed through an amplifier $(+40 \mathrm{~dB})$ and a $\frac{1}{3}$-octave filter to improve the signal-to-noise ratio, and then to the level recorder. The recorder was synchronized with the motor driving the microphone system.

It is extremely important to control the measuring frequency as the SPL difference will change drastically as a function of frequency especially at the higher frequencies. A frequency counter was used to keep the frequency within $\pm 1 \mathrm{~Hz}$ of the nominal value during the measurements.

The microphone (and the mounting equipment in its vicinity) must be kept very small to avoid unwanted disturbances of the sound field. For the present study, a subminiature electret microphone (Knowles, type BT-1759, $7.9 \times 5.6 \times 2.3 \mathrm{~mm}$ ) was used. Its directional characteristic at $10 \mathrm{kHz}$ differed maximally by $1.4 \mathrm{~dB}$
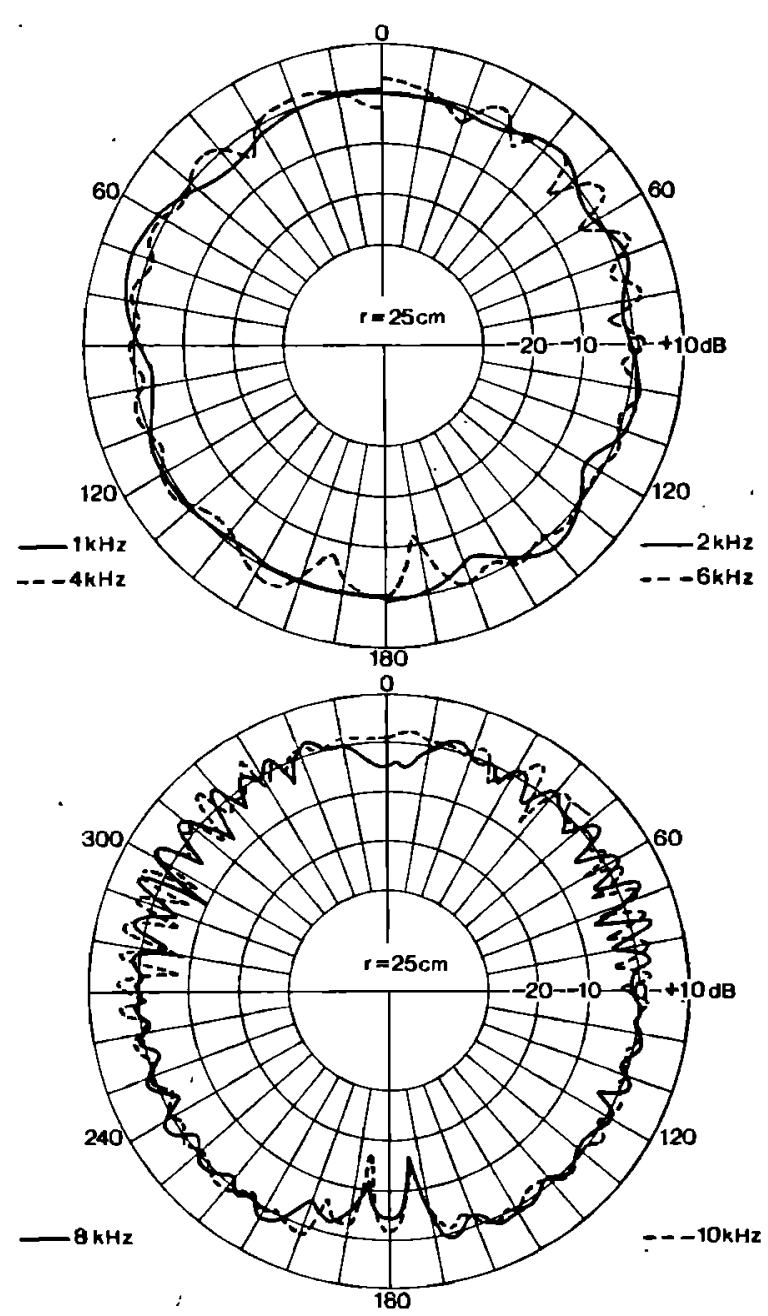

FIG. 6. Difference between SPL of regultant field and incident field $\Delta L_{p}(\mathrm{~dB})$ as a function of $\theta$, for $r=25 \mathrm{~cm}$. 
from that of an ideal omnidirectional microphone.

The sound source was chosen to provide an undisturbed sound field that could easily be described mathematically. The most straightforward would be a plane, progressive field, but this can not be generated over a large enough section of the room. The next field in order of simplicity is a simple radial field, i. e., the field generated by a zero-order source. A source with an approximately spherical characteristic up to $\mathbf{1 0}$ $\mathrm{kHz}$ was available, and was therefore chosen. This source, which is described in detail by Ingerslev et al. $(1967 / 68)$, has an omnidirectional characteristic that deviates less than $0.7 \mathrm{~dB}$ at frequencies up to $10 \mathrm{kHz}$.

The source was placed $3 \mathrm{~m}$ from the center of the head. This rather large distance was chosen because it permitted: (a) Measurements of the deformation of the field at distances up to $2 \mathrm{~m}$ from the surface of the manikin, and (b) the incident field to be approximately plane within the area containing the manikin.

In this investigation, the manikin was used as manufactured, i.e., without clothing and a wig, and the correct alignment of the manikin relative to the sound
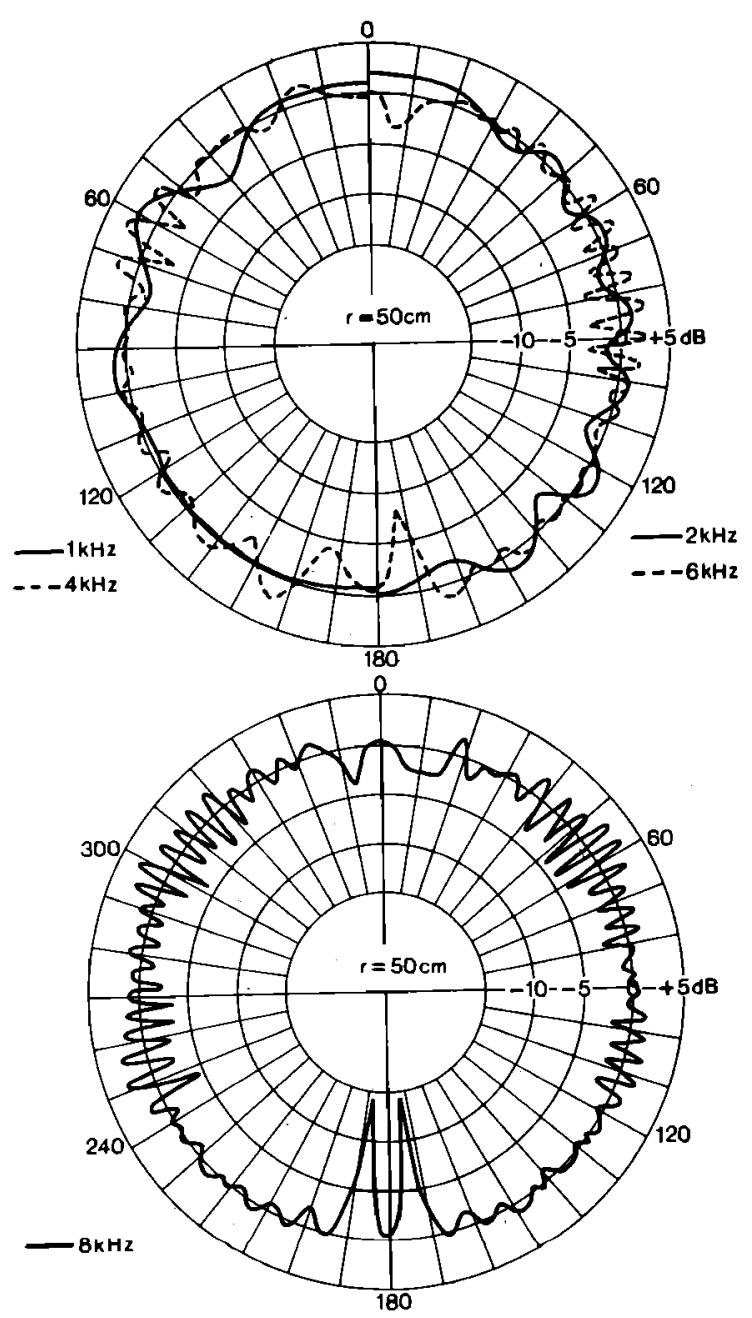

FIG. 7. Difference between SPL of resultant field and incident field $\Delta L_{p}(\mathrm{~dB})$ as a function of $\Theta$, for $r=50 \mathrm{~cm}$. source was defined as that which produced the most symmetric disturbance of the field around the manikin. So defined, this alignment varied somewhat from frequency to frequency and for different values of $r$, and it was decided that the manikin should be aligned for the distance $r=1 \mathrm{~cm}$ and the frequency $f=10 \mathrm{kHz}$. The alignment was carried out in two steps: First the head was placed on the torso (with two neck rings between) so that it "looked right" and the manikin was set facing the sound source. A curve of $L_{\text {ras }}$ as a function of $\theta$ was recorded. This was repeated with the manikin turned a little to either side of the first position, and in this way, a rough alignment was obtained. As a second step, the torso was maintained in the position found in step one and the head was turned slightly relative to the torso until the most symmetric curve (at $r=1 \mathrm{~cm}$ and $f=10$ $\mathrm{kHz}$ ) was obtained. The manikin then stayed in this position for the rest of the measurements.

It should be emphasized that the resultant field around the manikin at the higher frequencies is very sensitive to changes in the manikin's alignment. Other definitions of the correct alignment based, for instance, on the output from the microphones in the manikin's head

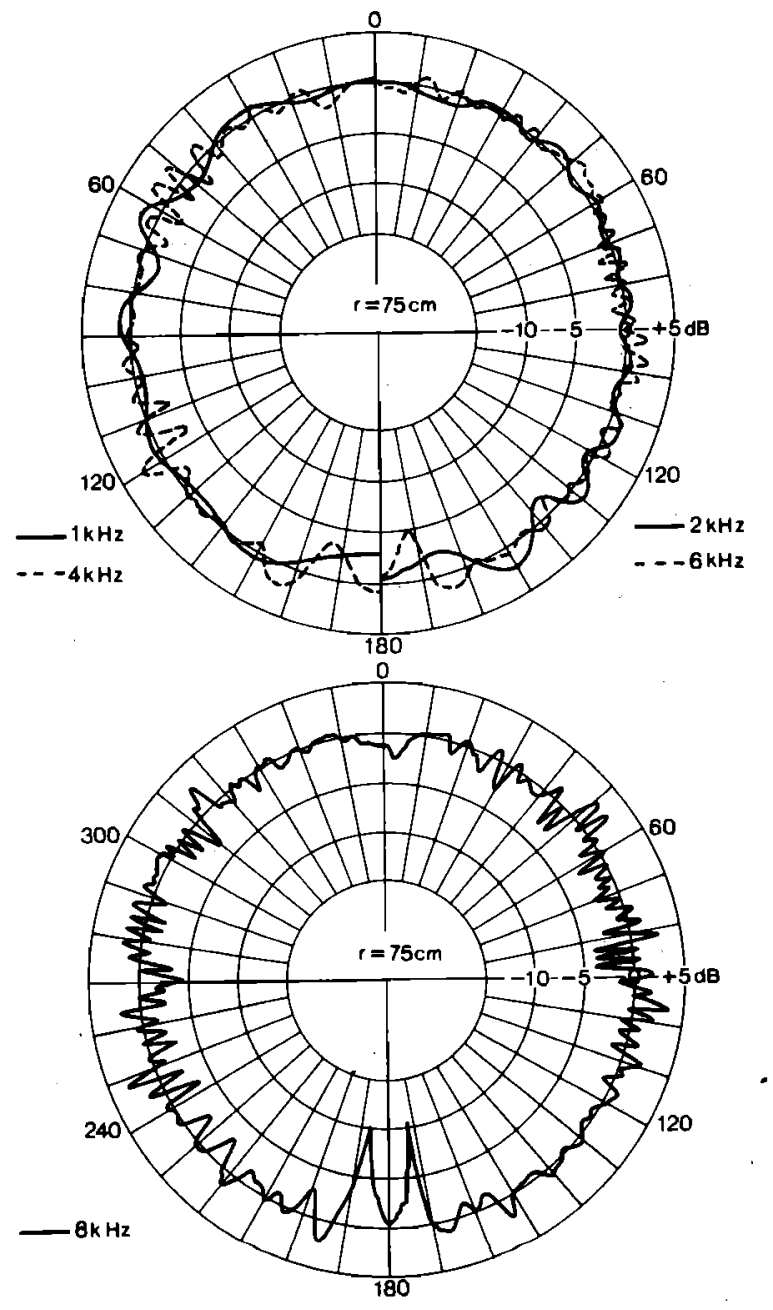

FIG. 8. Difference between SPL of resultant field and incident fleld $\Delta L_{p}(\mathrm{~dB})$ as a function of $\Theta$, for $r=75 \mathrm{~cm}$. 
will almost certainly lead to different values for the details of the resultant field.

\section{RESULtS}

A representative sample of results is shown in Figs. 3 through 14. Figures 3 through 11 present polar plots of $\Delta L$, as a function of $\theta$ ranging from the nearfield of the manikin to a distance of $1 \mathrm{~m}$. At the frequencies 1 to $6 \mathrm{kHz}, \Delta L_{p}$ is given only for values of $\theta$ in the interval $0^{\circ}$ to $180^{\circ}$ because the curves of $\Delta L_{b}$ generally are symmetrical, within a few decibels, around the median plane.

Figures 12, 13, and 14 present "three-dimensional" drawings of $\Delta L_{p}$ at 2,4 , and $6 \mathrm{kHz}$ and for $r$ from 1 to $30 \mathrm{~cm}$. This presentation facilitates the general view of the gradual development of the disturbance of the field around the manikin.

\section{SUMMARY}

The results show that the manikin causes a deformation $\left(\Delta L_{\phi}\right)$ of the incident field in front of itself that is

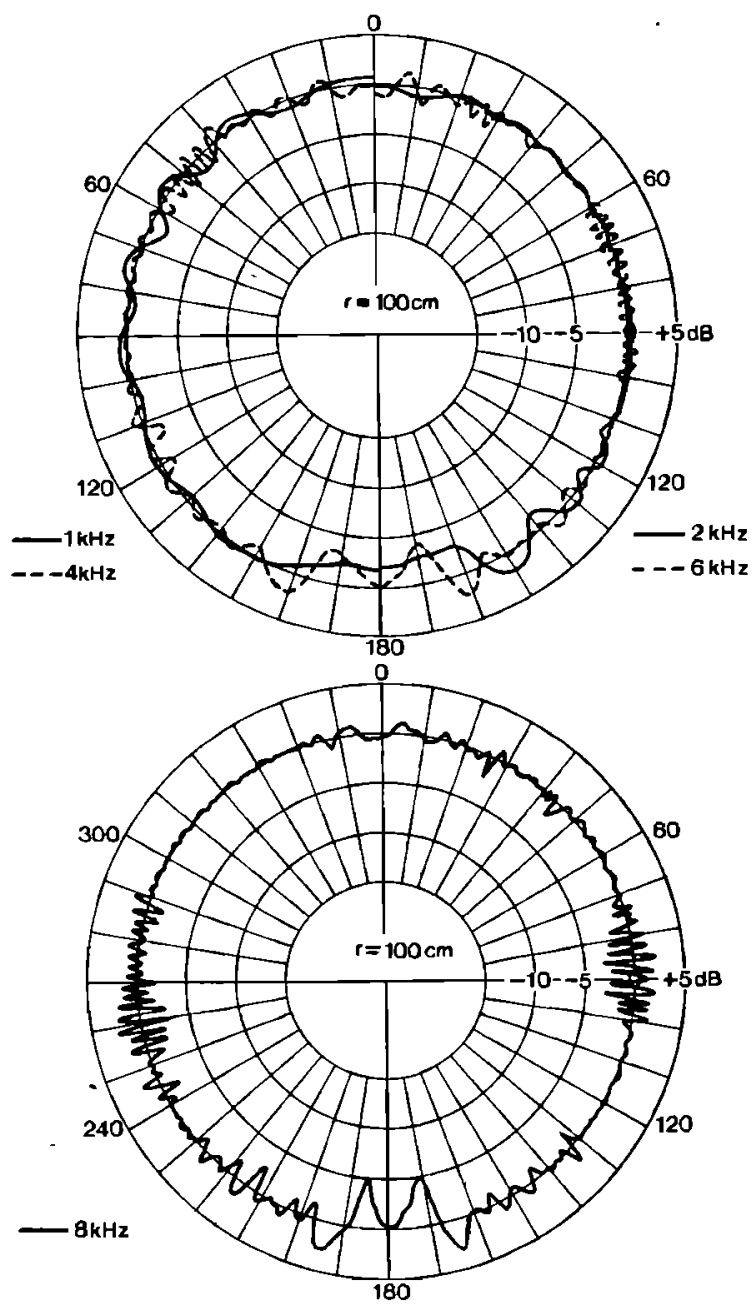

FIG. 9. Difference between SPL of resultant field and incident field $\Delta L_{b}(\mathrm{~dB})$ as a function of $\theta$, for $r=100 \mathrm{~cm}$.
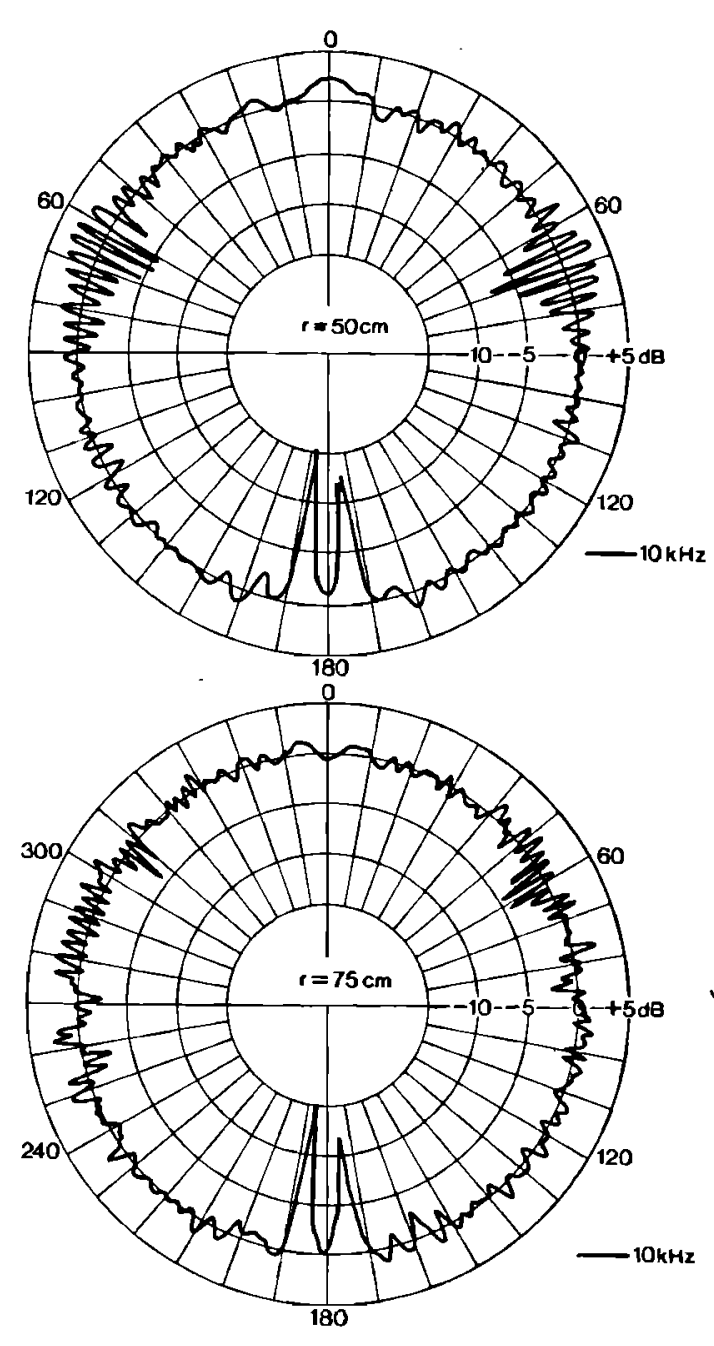

FIG. 10. Difference between SPL of resultant field and incident field $\Delta L_{b}(\mathrm{~dB})$ as a function of $\Theta$ at $10 \mathrm{kHz}$, for $r=50$ and $75 \mathrm{~cm}$.

less than about $2 \mathrm{~dB}$ at a distance of $50 \mathrm{~cm}$. At $100 \mathrm{~cm}$ this deformation amounts to about $1 \mathrm{~dB}$. At the back of the manikin, i.e., within the angles from $170^{\circ}$ to

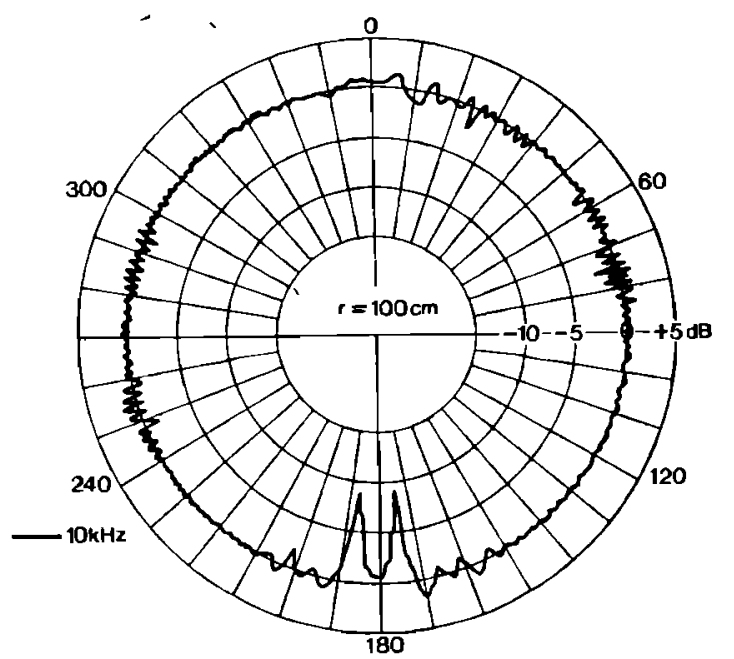

FIG. 11. Difference between SPI of resultant field and incident field $\Delta L_{p}(d B)$ as a function of $\theta$ at $10 \mathrm{kHz}$ for $r=100 \mathrm{~cm}$. 


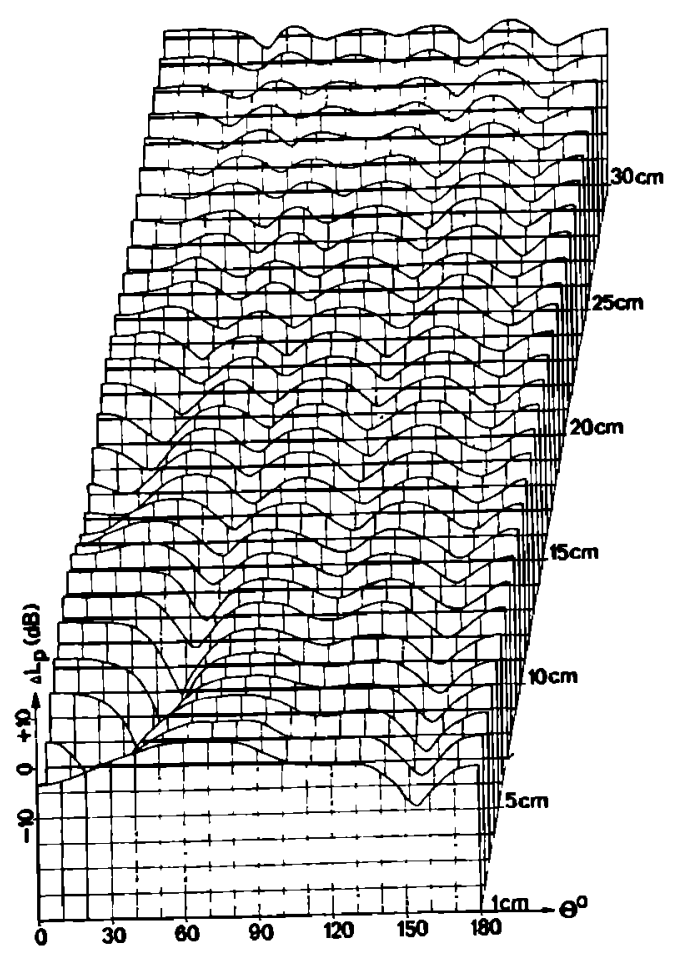

FIG. 12. $\Delta L_{p}(\mathrm{~dB})$ versus $\theta$ at distances from 1 to $30 \mathrm{~cm}$, for $f=2 \mathrm{kHz}$. The heavy line in the coordinate net indicates $0 \mathrm{~dB}$ throughout the drawing.

$190^{\circ}$, there exist sharp destructive interference minima in $\Delta L_{p}$, which still amount to as much as $9 \mathrm{~dB}$ at a distance of $100 \mathrm{~cm}$ from the manikin at $10 \mathrm{kHz}$. Apart

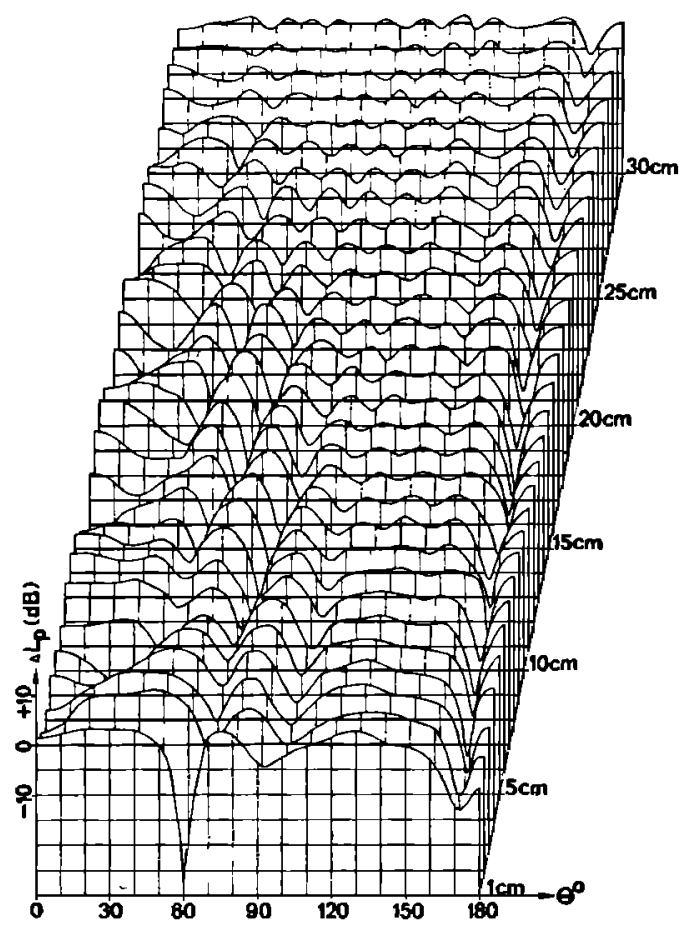

FIG. 13. $\Delta L_{p}(\mathrm{~dB})$ versus $\theta$ at distances from 1 to $30 \mathrm{~cm}$, for $f=4 \mathrm{kHz}$. The heavy line in the coordinate net indicates $0 \mathrm{~dB}$ throughout the drawing.

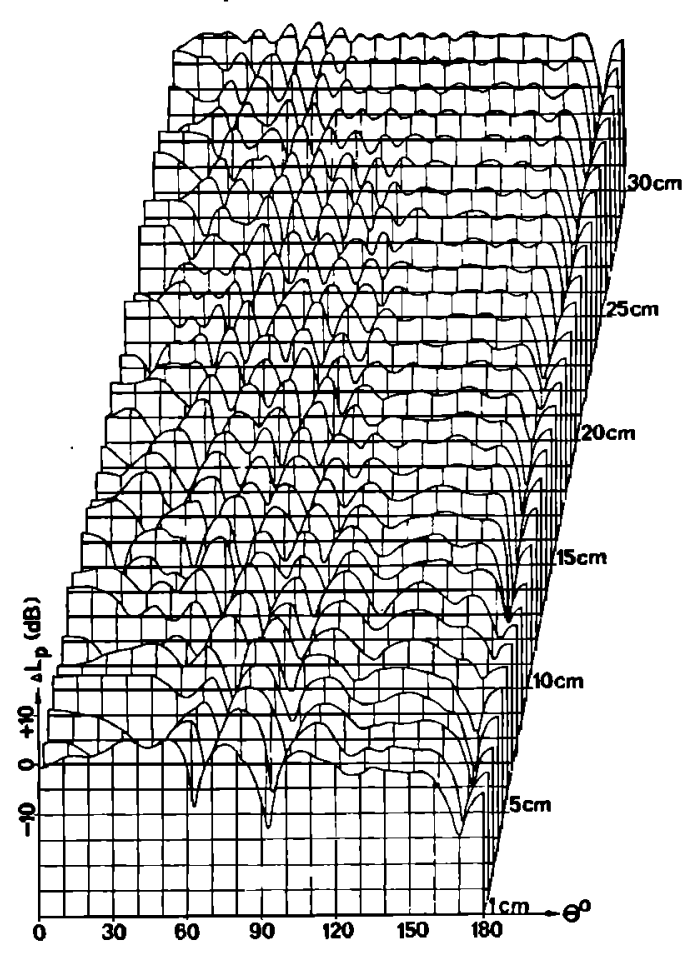

FIG. 14. $\Delta L_{p}$ (dB) versus $\theta$ at distances from 1 to $30 \mathrm{~cm}$, for $f=6 \mathrm{kHz}$. The heavy line in the coordinate net indicates $0 \mathrm{~dB}$ throughout the drawing.

from these minima, the maximum value of $\Delta L_{b}$ at 50 $\mathrm{cm}$ is from $+3 \mathrm{~dB}$ to $-7 \mathrm{~dB}$ (over the range $60^{\circ} \leqslant \theta \leqslant 80^{\circ}$ ) and approximately $\pm 2.5 \mathrm{~dB}$ (over the range $80^{\circ} \leqslant \theta$ $\leqslant 110^{\circ}$ ) at $100 \mathrm{~cm}$.

\section{ACKNOWLEDGMENTS}

The author wishes to express his gratitude to the foundation "William Demants og Hustru Ida Emilies Fond" for their financial support, the firm OTICON for the loan of the manikin KEMAR, and Mr. O. Juhl Pedersen and Mr. T. Poulsen for their help and guidance during the work on my M.Sc, dissertation on which this article is based.

Burkhard, M. D., and Sachs, R. M. (1975). "Anthropometric manikin for acoustic research," J. Acoust. Soc. Am. 58, 214-222.

Burkhard, M. D. (1978). Manikin Measurements, Conference Proceedings (IRPI, Elk Grove, IL), pp. 53-56.

Ingerslev, F., Pedersen, O. J., and Møller, P. K. (1967/68). "New rooms for acoustic measurements at the Danish Technical University," Acustica 19, 185-199.

Kuhl, W., and Plantz, R. (1975). "Artificial-head stereophony and other methods of sound transmission compared with natural hearing." EBU Rev. -Tech. Part 151-129.

Preves, D. A. (1978). Manikin Measurements, Conference Proceedings (IRPI, Eik Grove, IL), pp. 43-48.

Wilkens, H. (1972). "Kopfbezügliche Stereophonie-ein Hilfsmitted für Vergleich und Beurteilung verschiedener Raumeindrücke," Acustica 26, 213-221. 